\title{
FLUID-SOLID INTERACTION IN THE CASE OF PIPING EROSION: VALIDATION OF A SPH-ALE CODE
}

\author{
${\text { Jessica } \mathrm{Sjah}^{1 *} \text {, Eric Vincens }}^{2}$ \\ ${ }^{1}$ Department of Civil Engineering, Faculty of Engineering, Universitas Indonesia, \\ Kampus UI Depok, Depok 16424, Indonesia \\ ${ }^{2}$ University of Lyon, LTDS, UMR CNRS 5513, École Centrale de Lyon, \\ 36 avenue Guy de Collongue, 69134 Écully CEDEX, France
}

(Received: February 2017 / Revised: May 2017 / Accepted: October 2017)

\begin{abstract}
This paper presents a set of numerical simulations of different 2D boundary-value problems in order to validate a "smoothed-particle hydrodynamics"-"arbitrary Lagrangian-Eulerian" (SPHALE) code. This code is intended to be used to study, among other things, the problem of piping erosion in dams and dikes. The case of viscous fluid flows around a fixed cylinder was first examined. Different Reynolds numbers and different shapes for the cylinder were considered. The drag coefficient, lift coefficient, pressure coefficient, and Strouhal number were compared with previous studies from the literature. Next, a validation of the case of a Poiseuille flow between smooth pipe walls with $\mathrm{Re}=100$ was provided. The friction coefficient was computed and compared to existing analytical solutions.
\end{abstract}

Keywords: Hydrodynamics; Internal erosion; Pipe; Viscous fluid flow

\section{INTRODUCTION}

Internal erosion is one of the most common failures found in hydraulic structures (Foster et al., 2000; Fell \& Fry, 2007; Xu \& Zhang, 2009). Internal erosion is a phenomenon in which particles from the core or the foundation of a dike are detached and transported over great distances due to hydraulic efforts. Piping erosion, also called a concentrated leak, is the most common form of erosion observed on a site.

Piping erosion is related to the interaction between the flow in the pipe and the particles constituting the pipe wall. The hydrodynamic forces generate a load on the pipe-wall particles, and if the forces are high enough, they could induce the detachment of some particles from the wall, leading to the enlargement of the pipe's diameter. As a preliminary study of this complex problem, the case of a smooth fixed pipe is considered.

Different numerical methods involving the fluid phase have been used to study the phenomenon of erosion. The finite volume method, which is a continuum approach, has been used by Lachouette et al. (2009) and by Mercier (2013) to solve boundary-value problems on the scale of a sample or of a hydraulic structure. On a sample scale and/or particle scale, this problem has been solved using a discontinuous approach for the fluid, such as the lattice Boltzmann method (Sibille et al., 2012; Mercier, 2013).

An existing particle-based code, called ASPHODEL, which is based on the smoothed-particle

\footnotetext{
*Corresponding author's email: jessicasjah@ui.edu, Tel: +62-21-7270029, Fax: +62-21-7874878

Permalink/DOI: https://doi.org/10.14716/ijtech.v8i6.729
} 
hydrodynamics (SPH) method developed by ANDRITZ in partnership with the Laboratory of Fluid Mechanics and Acoustics (Laboratoire de Mécanique des Fluides et d'Acoustique LMFA) at École Centrale de Lyon, was selected for this study. It is based on a weak and conservative formulation of Euler equations, and adopts a Lagrangian-Eulerian arbitrary (ALE) description of the fluid flow provided by Tait's state equation. In this study, the capability of the SPH-ALE method is evaluated in the context of piping erosion.

The simple case of a viscous fluid flow around a 2D fixed cylinder with different types of section is first studied. The drag force, lift force, pressure coefficient around the cylinder, and Strouhal number are examined and compared to the results obtained from the literature for different Reynolds numbers.

The SPH-ALE method on a sample scale is validated by modeling the viscous fluid flow between smooth walls (Poiseuille flow). The coefficient of friction is calculated and compared with the analytical solution from the literature.

\section{SPH-ALE METHOD}

The SPH method is a meshless method in which the computational domain is discretized using particles (Monaghan, 1992). The physical quantities of a computational particle are evaluated by interpolating the corresponding physical properties associated with the neighboring particles within the influence domain of the computational particle (Figure 1). The SPH-ALE method was developed by Vila (1999). This method is based on the standard SPH method and adopts a dual-flow description known as ALE. The reference frame moves with an arbitrarily velocity $\left(v_{0}\right)$. The discretized forms of the conservation laws for a viscous flow are written as follows:

$$
\left\{\begin{array}{c}
\frac{d}{d t}\left(x_{i}\right)=v_{0}\left(x_{i}, t\right) \\
\frac{d}{d t}\left(\omega_{i}\right)=\omega_{i} \sum_{j \in D_{i}} \omega_{j}\left(v_{0}\left(x_{j}\right)-v_{0}\left(x_{i}\right)\right) \nabla_{i} W_{i j} \\
\frac{d}{d t}\left(\omega_{i} \rho_{i}\right)=-\omega_{i} \sum_{j \in D_{i} \cup \partial D_{i}} \omega_{j} 2 \rho_{E, i j}\left(v_{E, i j}-v_{0}\left(x_{i j}, t\right)\right) \cdot A_{i j} \\
\frac{d}{d t}\left(\omega_{i} \rho_{i} v_{i}\right)=-\omega_{i} \sum_{j \in D_{i} \cup \partial D_{i}} \omega_{j} 2\left(\rho_{E, i j} v_{E, i j} \otimes\left(v_{E, i j}-v_{0}\left(x_{i j}, t\right)\right)+p_{E, i j}\right) \cdot A_{i j}+\omega_{i} \rho_{i} g \\
+\omega_{i} \rho_{E, i j} \sum_{j \in D_{i} \cup \partial D_{i}} \omega_{j}\left(\mu_{i}+\mu_{j}\right) \frac{x_{i j} A_{i j}}{\left\|x_{i j}\right\|^{2}+\eta^{2}} v_{i j}
\end{array}\right.
$$

Plus the following:

$$
A_{i j}=\left\{\begin{array}{c}
\nabla_{i} W_{i j} \text { if } j \in D_{i} \text { (fluid particle) } \\
W_{i j} n_{j} \text { if } j \in D_{i} \text { (boundary particle) }
\end{array}\right.
$$

where $\left(\rho_{E, i j} ; v_{E, i j}\right)$ is the upwind solution for the Riemann problem at the midpoint between pairs of neighboring particles $i$ and $j$. The solution of the Riemann problem is obtained by extrapolating the field variables at the interface following the monotone upstream-centered schemes for the conservation laws (MUSCL) scheme. A linearized approximate Riemann solver computes a mean for these extrapolated states and expresses the corresponding solution analytically. The viscous term is introduced here using the Morris model (Morris et al., 1997). To close the system of Equation 1, Tait's equation of state is considered (Tait, 1888). The 
kernel function is a Wendland C4 function. More details on the SPH-ALE method can be found in Marongiu (2007) and Leduc (2010).

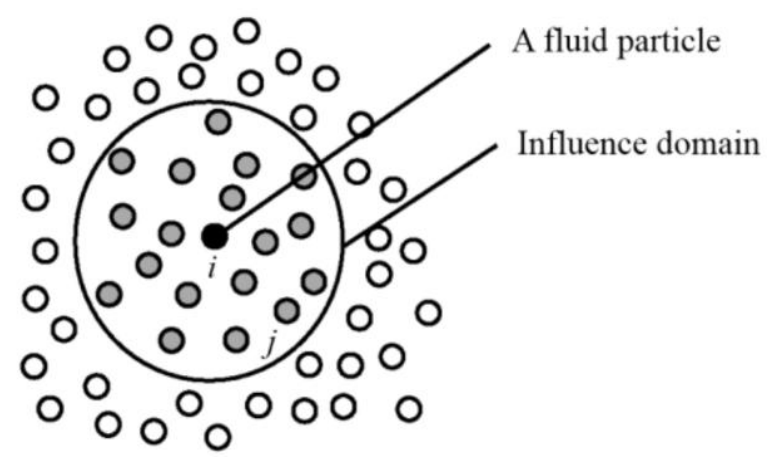

Figure 1 Computational domain discretized by particles

\section{FLOW AROUND A FIXED CYLINDER}

\subsection{Flow around a Circular Cylinder}

A fixed and isolated circular cylinder of diameter $D$ is modeled in $2 \mathrm{D}$, as a disk in a rectangular computational domain, using the SPH-ALE method with a Eulerian description (Figure 2). The distribution of the fluid particles remains constant and fixed throughout the simulation by choosing the Eulerian mode. The non-reflective boundary conditions are applied to the inlet and outlet of the system with a velocity depending on the Reynolds number $(R e)$ and zero pressure, respectively. Periodic conditions are applied to the upper and lower boundaries of the system.

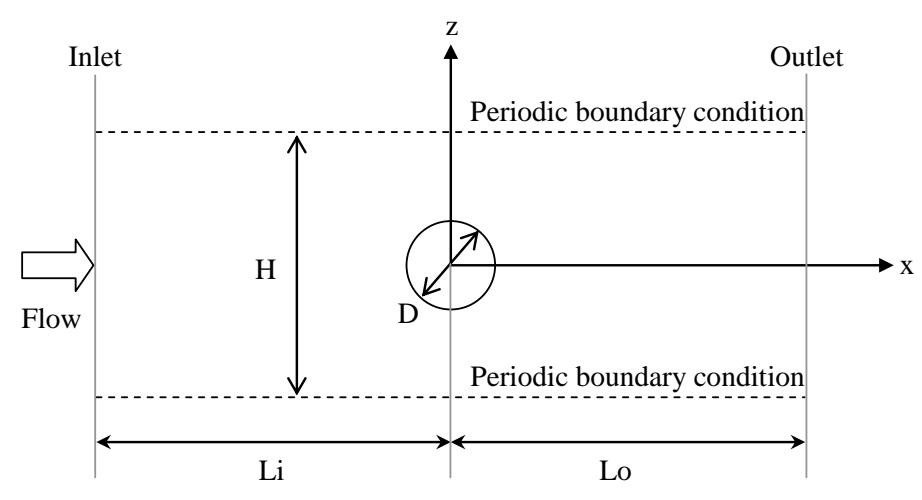

Figure 2 System modeled for flow around a fixed circular cylinder

\subsubsection{Calibration of parameters}

It is of paramount importance to first identify a set of parameters related to the dimensions of the computational domain in order to obtain a compromise between the quality of the results and the calculation time for the numerical simulations. Indeed, the boundary conditions must be located at a sufficient distance from the cylinder so that they do not influence the quality of the results. The optimum value was found for $H$ equal to $16 D$, which confirms the work of Behr et al. (1995).

Moreover, this compromise must also involve the discretization of the computational domain. Two parameters for discretization were studied: the discretization size of the fluid particles $\left(r_{0}\right)$ and the refinement factor $(R R)$. The fluid domain is discretized by fluid particles having a cubic unit volume (square in 2D cases) with the discretization size of $r_{0}$. The refinement of the size of 
the fluid particles around the wall is to compensate for the insufficient accuracy of the calculations around the obstacles, which is the cylinder in this case. The choice of $r_{0}=\mathrm{D} / 40$ and $R R=0.5$ made it possible to obtain a reasonable computation time while comparing the quantitative results obtained by other numerical methods (Ghias et al., 2007). More details about these two studies can be found in Sjah et al. (2013).

\subsubsection{Validation for different Re}

Different flow regimes can be observed depending on the Reynolds number. Three Reynolds numbers $(40,100$, and 1,000) are considered, and the results obtained using the SPH-ALE method are compared with those obtained from other numerical methods and experimental results. Some dimensionless results have been defined: the drag coefficient due to pressure contribution $\left(C_{D p}\right)$, the lift coefficient due to pressure contribution (maximum value of $C_{L m a x}$ or effective value of $\left.C_{L r m s}\right)$, the pressure coefficient around a cylinder $\left(C_{P}\right)$, and the Strouhal number $(S t)$ as shown in Table 1.

Table 1 Results for viscous flow around a circular cylinder

\begin{tabular}{|c|c|c|c|c|c|}
\hline$R e=40$ & $C_{D p}$ & & $\mathrm{C}_{\mathrm{p}-0^{\circ}}$ & $\mathrm{C}_{\mathrm{p}-180^{\circ}}$ & \\
\hline SPH-ALE method (ASPHODEL) & 1.14 & & 1.33 & -0.56 & \\
\hline Other numerical methods & & & & & \\
\hline Finite volume method (Dröge, 2007) & 1.02 & & 1.18 & & \\
\hline $\begin{array}{l}\text { Spectral element method (Posdziech \& Grundmann, 2007) } \\
\text { Experiment }\end{array}$ & 0.98 & & & -0.50 & \\
\hline Grove et al. (1964, cited in Grove et al., 2006) & & & 1.17 & -0.50 & \\
\hline$R e=100$ & $C_{D p}$ & $\mathrm{C}_{\mathrm{Lrms}}$ & $\mathrm{C}_{\mathrm{p}-0^{\circ}}$ & $\mathrm{C}_{\mathrm{p}-180^{\circ}}$ & $S t$ \\
\hline $\begin{array}{l}\text { SPH-ALE method (ASPHODEL) } \\
\text { Other numerical methods }\end{array}$ & 1.07 & 0.19 & 1.22 & -0.72 & 0.173 \\
\hline $\begin{array}{l}\text { Finite volume method (Rajani et al., 2009) } \\
\text { Experiments }\end{array}$ & 1.00 & 0.18 & 1.05 & -0.72 & 0.157 \\
\hline Henderson (1995) & 1.00 & & & & \\
\hline $\begin{array}{l}\text { Homann (1936, cited in Zdravkovich, 1997) } \\
\text { Tritton (1959, cited in Zdravkovich, 1997) }\end{array}$ & & & 1.04 & -0.65 & 0.165 \\
\hline$R e=1,000$ & $C_{D p}$ & $C_{L \max }$ & $\mathrm{C}_{\mathrm{p}-0^{\circ}}$ & $\mathrm{C}_{\mathrm{p}-180^{\circ}}$ & St \\
\hline $\begin{array}{l}\text { SPH-ALE method (ASPHODEL) } \\
\text { Other numerical methods }\end{array}$ & 1.52 & 1.39 & 1.16 & -1.66 & 0.242 \\
\hline $\begin{array}{l}\text { Finite element method (Mittal et al., 1997) } \\
\text { Finite difference method (Ghias et al., 2007) } \\
\text { Experiment }\end{array}$ & 1.40 & 1.37 & 1.00 & -1.67 & $\begin{array}{l}0.245 \\
0.243\end{array}$ \\
\hline Thom (1928, cited in Zdravkovich, 1997) & & & 1.00 & -0.80 & 0.210 \\
\hline
\end{tabular}

For $R e=40$, the flow is laminar with a fixed point of separation and symmetric vortices. The stationary solution is obtained from $t=150 \mathrm{~s}$, as shown in Figure $3 \mathrm{a}$ and $3 \mathrm{~b}$. The mean $C_{p}$ distribution around the circular cylinder given by SPH-ALE method is farther from the reference for $\theta=60-140^{\circ}$ (Figure 3c). The SPH-ALE method also overestimates the value of $C_{p}$ by $13 \%$ at the stagnation point of the circular cylinder, which gives a value of $C_{D p}$ that is $12 \%$ higher than other numerical methods, in this case the finite volume method (Dröge, 2007). Further analysis suggests the limitations of the Morris viscous model (Morris et al., 1997) used here.

For $R e=100$, the flow is laminar with the formation of a wake behind the circular cylinder, which gives a non-stationary and periodic solution (Figure $4 \mathrm{a}$ and $4 \mathrm{~b}$ ). Figure $4 \mathrm{c}$ reveals that the mean $C_{p}$ distribution obtained by the SPH-ALE method is close to the one obtained by the finite volume method (Rajani et al., 2009), except at the stagnation point. The results are summarized in Table 1 and generally show deviations of the order of $5 \%$ to $8 \%$ with other studies which is acceptable. 

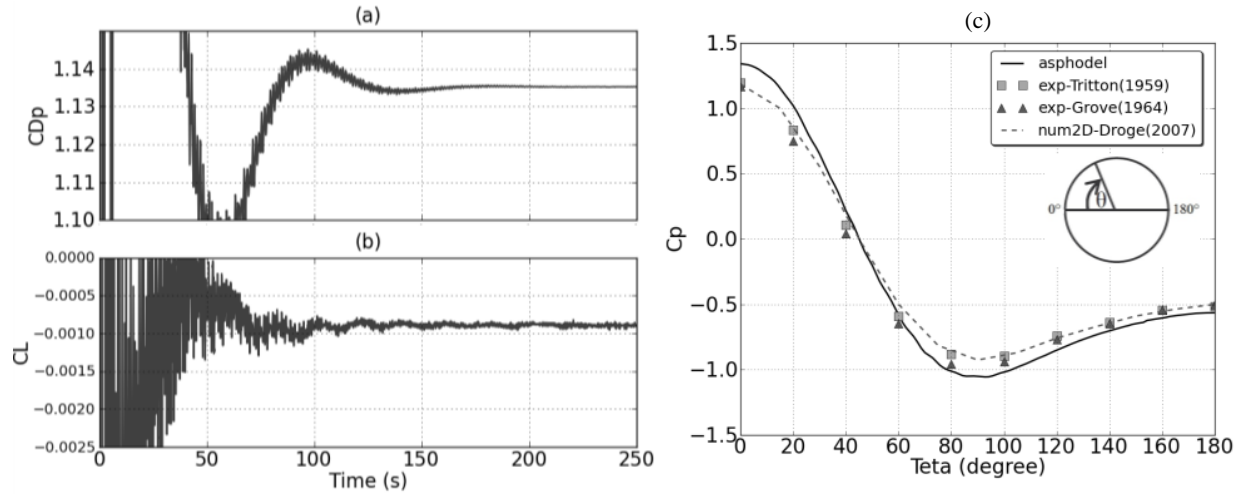

Figure 3 Results for: (a) $C_{D p}$; (b) $C_{L}$; and (c) mean $C_{p}$ around a circular cylinder compared to the results given in the literature for $R e=40$
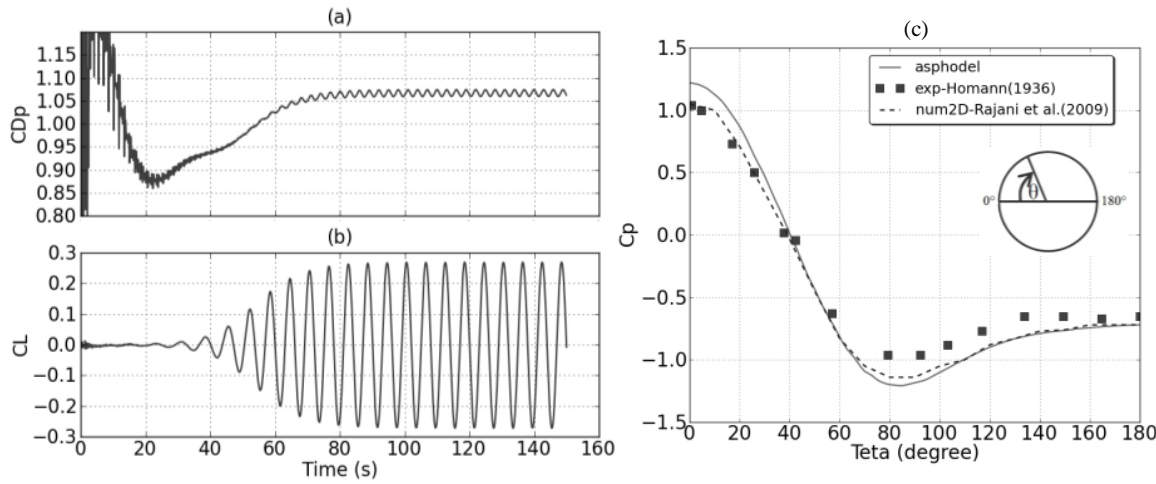

Figure 4 Results for: (a) $C_{D p}$; (b) $C_{L}$; and (c) mean $C_{p}$ around a circular cylinder compared to the results given in the literature for $R e=100$

For $R e=1,000$, the flow is laminar but 3D phenomena start to appear in experiments and should be taken into account in the numerical modeling. Herein, this latter aspect will not be taken into account and the simulations will remain 2D. The solution is non-stationary and oscillates with a large amplitude (Figure 5a and 5b). Figure 5c indicates that the mean $C_{p}$ distribution around the circular cylinder obtained by the SPH-ALE method is close to one obtained using a finite difference method (Ghias et al., 2007), except at the stagnation point. In Table 1, the results obtained from the SPH-ALE method give a maximum difference of $9 \%$ to the other results obtained that are given in the literature, which is acceptable.
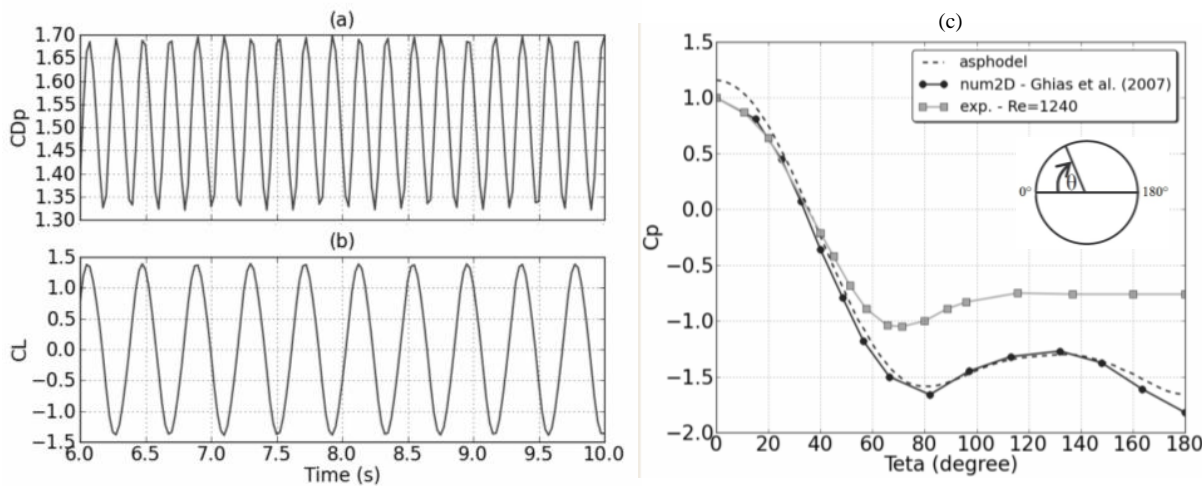

Figure 5 Results for: (a) $C_{D p}$; (b) $C_{L}$; and (c) mean $C_{p}$ around a circular cylinder compared to the results given in the literature for $R e=1,000$ 


\subsection{Flow around a Square Cylinder}

For complex geometries, such as a square cylinder, the drag increases, as does the width of the wake, because the flow at the front side of the square is deflected $90^{\circ}$ over a certain distance. The results for $C_{D p}$ and $C_{l}$ are shown in Figure $6 \mathrm{a}$ and $6 \mathrm{~b}$. Figure $6 \mathrm{c}$ shows that the mean $C_{p}$ distribution around the square cylinder obtained using the SPH-ALE method is close to the one obtained using the finite element method (Bao et al., 2012), except at the stagnation point (where there is an overestimation of 23\%). The results obtained using the SPH-ALE method and the literature are given in Table 2. Illustrations of the velocity and pressure fields for the fluid particles are given in Figure 7.
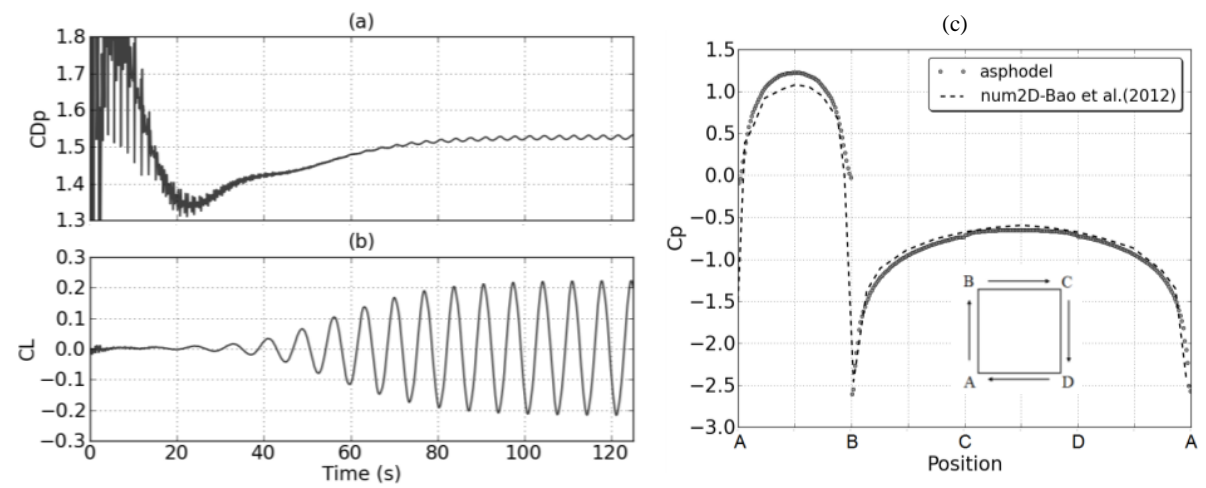

Figure 6 Results for: (a) $C_{D p}$; (b) $C_{L}$; and (c) mean $C_{p}$ around a square cylinder compared to the results given in the literature for $R e=100$

Table 2 Results for viscous flow around a square cylinder

\begin{tabular}{lcccc}
\hline$R e=100$ & $C_{D p}$ & $C_{\mathrm{Lrms}}$ & $\mathrm{C}_{\mathrm{p}-0^{\circ}}$ & $S t$ \\
\hline SPH-ALE method (ASPHODEL) & 1.576 & 0.173 & 1.23 & 0.165 \\
Other numerical methods & & & & \\
Finite element method (Bao et al., 2012) & & 0.180 & 1.00 & 0.145 \\
Finite volume method (Sahu et al., 2009) & 1.441 & 0.188 & & 0.149 \\
Experiment & & & & \\
Norberg (1993) & & & & 0.143 \\
\hline
\end{tabular}

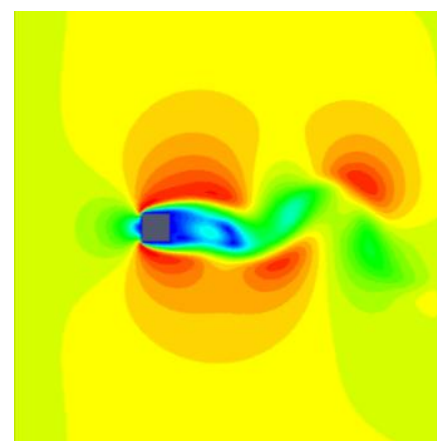

(a)

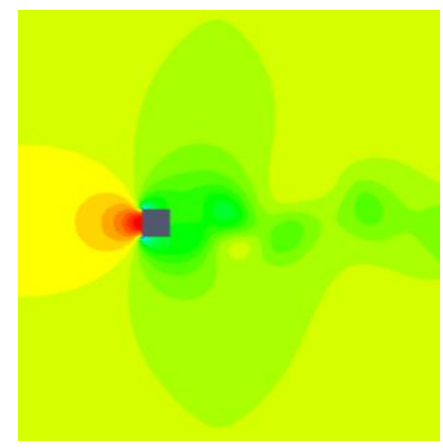

(b)

Figure 7 Distribution of: (a) velocity field; and (b) pressure field of fluid particles for flow around a square cylinder of $R e=100$

\section{POISEUILLE FLOW}

The validation of the Poiseuille flow between two fixed, smooth walls of finite length for $R e=$ 100 was carried out (Figure 8). This flow is modeled in a rectangular computational domain 
using the SPH-ALE method with the Eulerian description. The computational domain was paved by fluid particles with a uniform discretization of $H / 40$. The fluid flow is induced by imposing an average speed at the inlet and a condition of zero static pressure at the outlet. When the fluid flows between two fixed, smooth walls, the fluid velocity evolves from a uniform velocity into a parabolic velocity profile (a fully developed flow) along the pipe. The purpose of this study is to obtain the Darcy friction coefficient and to compare it to the existing analytical solutions. This coefficient was calculated in the zone where the fully developed flow is reached.

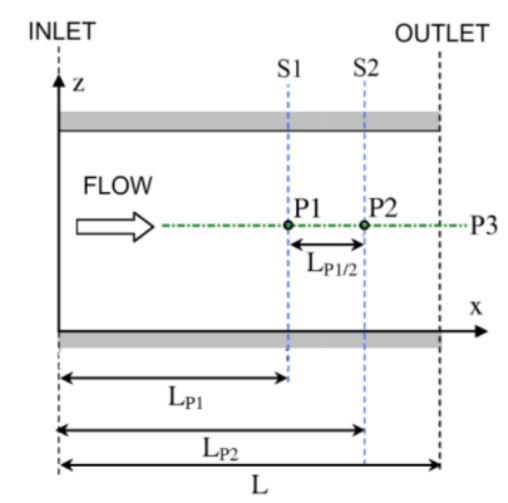

Figure 8 System for Poiseuille flow

The two measurement points are selected in the zone located after the entrance length, $L_{e}$, to get the fully developed flow regime (Kays \& Crawford, 1993). The length of the wall pipe is determined by adding $5 H$ to $L_{e}$, as follows:

$$
L=L_{e}+5 H=0.05 \times \operatorname{Re} \times H+5 H
$$

The pressure drop $\left(\triangle P_{P 1 / P 2}\right)$, the friction coefficient $\left(f_{D}\right)$, and the Poiseuille number $\left(P_{o}\right)$ are calculated and compared to the analytical solutions. The friction coefficient, $f_{D}$, can be computed from the following equation:

$$
f_{D}=-\frac{\Delta p}{\Delta x} \frac{2 H}{\rho v^{2}}=-\frac{p_{P 2}-p_{P 1}}{L_{P 1 / P 2}} \frac{2 H}{\rho v_{P 1 / P 2}^{2}}
$$

The two measurement points, $\mathrm{P} 1$ and $\mathrm{P} 2$, used to compute $f_{D}$ were chosen (Figure 8 ). The sections related to points $\mathrm{P} 1$ and $\mathrm{P} 2$ are defined as $\mathrm{S} 1$ and $\mathrm{S} 2 . L_{P 1 / P 2}$ is the distance between points $\mathrm{P} 1$ and $\mathrm{P} 2 . p_{P 2-P 1}$ is the pressure difference between points $\mathrm{P} 1$ and $\mathrm{P} 2 . \rho$ is the water density. $v_{P 1 / P 2}$ is the average velocity between points $\mathrm{P} 1$ and $\mathrm{P} 2 . \Delta p$ is the pressure drop that is obtained from the generalized Bernoulli theorem. For Poiseuille flow at a steady state, by considering the incompressible fluid ( $\operatorname{div} v=0)$, the velocities at points 1 and 2 are equal and the pressure drop is then deduced from the difference in static pressure between the two measurement points.

The study of the Poiseuille flow for $R e=100$ associated with a wall pipe with length equal to $10 H$ requires the use of 16,000 fluid particles with a uniform discretization of $H / 40$. The friction coefficient was calculated between $6 H$ and $8 H$. The results for $\triangle P_{P 1 / P 2}, f_{D}$, and $P_{o}$ obtained using the SPH-ALE method give differences of $14 \%, 12 \%$, and $13 \%$, respectively, compared to the analytical solutions (Table 3), which is acceptable. However, to increase the quantitative results, a finer discretization than the one previously taken was used, of $r O=H / 100$ 
or 2.5. This finer discretization allows the reduction of the difference from the analytical solution by $8 \%$.

Table 3 Numerical simulation of the Poiseuille flow with $r_{0}=H / 40$

\begin{tabular}{cccc}
\hline \multirow{2}{*}{$R e=100$} & \multirow{2}{*}{ Analytic } & \multicolumn{2}{c}{ SPH-ALE method } \\
\cline { 3 - 4 } & & Magnitude & Error $(\%)$ \\
\hline$\Delta P_{P I / P 2}$ & $3.842 \times 10^{-3}$ & $4.380 \times 10^{-3}$ & 14 \\
$f_{D}$ & $2.399 \times 10^{-1}$ & $2.681 \times 10^{-1}$ & 12 \\
$P_{o}$ & 24 & 27.2 & 13 \\
\hline
\end{tabular}

\section{CONCLUSION}

The capacity of the ASPHODEL code based on the SPH-ALE method to address the problem of piping erosion phenomenon in hydraulic structures was investigated herein; a primary study was conducted before a more complex investigation was carried out.

On a particle scale, the case of a viscous flow around a fixed cylinder was provided. The SPHALE method gave relative differences of $12 \%, 7 \%$, and $8.6 \%$ for $R e=40,100$, and 1,000, respectively, for the drag coefficient due to the pressure contribution. The SPH-ALE method gave a result for the lift coefficient, due to the pressure contribution, with relative differences equal to $5.5 \%$ and $1.5 \%$ for $R e=100$ and 1,000 , respectively compared to the literature. For the Strouhal number, the relative deviations are at most $8 \%$ for $R e=100$, but can reach $15 \%$ for $R e=1,000$. In this case, a 3D model would be necessary to approximate the experimental phenomena. It seems that the error in the results at the stagnation point of the cylinder came from the viscous model implemented in the code. However, these results were acceptable as a first quantitative result for the numerical simulations. The study of viscous flow around a square cylinder was carried out to test the ability of the SPH-ALE method to process complex geometries. The deviations found were of the same order of magnitude as for the circular cylinder, which validated the numerical code.

The study on a sample scale was the first stage for the direct validation of the ability of ASPHODEL code to address the problem of piping erosion. Next, a case study of a viscous flow between smooth walls (Poiseuille flow) was carried out. The different properties investigated by the numerical simulation showed a departure of about $13 \%$ from the existing analytical solutions. This difference was acceptable for a first quantitative estimate in geomechanical applications. A smaller departure could be obtained by using a finer discretization at the expense of the computation time.

\section{ACKNOWLEDGEMENT}

The authors would like to thank Jean-Christophe Marongiu (ANDRITZ Hydro R\&D) and Joëlle Caro of the LMFA for the quality exchanges around this work and their support, both scientific and informatic.

\section{REFERENCES}

Bao, Y., Wu, Q., Zhou, D., 2012. Numerical Investigation of Flow around an Inline Square Cylinder Array with Different Spacing Ratios. Computers \& Fluids, Volume 55, pp. 118131

Behr, M., Hastreiter, D., Mittal, S., Tezduyar, T.E., 1995. Incompressible Flow Past a Circular Cylinder: Dependence of the Computed Flow Field on the Location of the Lateral 
Boundaries. Computer Methods in Applied Mechanics and Engineering, Volume 123(1-4), pp. 309-316

Colagrossi, A., Bouscasse, B., Antuono, M., Marrone, S., 2012. Particle Packing Algorithm for SPH Schemes. Computer Physics Communications, Volume 183(8), pp. 1641-1653

Dröge, M.T., 2007. Cartesian Grid Methods for Turbulent Flow Simulation in Complex Geometries. Ph.D. Thesis, University of Groningen, Groningen, Netherlands

Fell, R., Fry, J-J., 2007. State of the Art of Assessing the Likelihood of Internal Erosion of Embankment Dams, Water Retaining Structures and their Foundations. Internal Erosion of Dams and Their Foundations, pp. 1-23

Foster, M., Fell, R., Spannagle, M., 2000. The Statistics of Embankment Dam Failures and Accidents. Canadian Geotechnical Journal, Volume 37(5), pp. 1000-1024

Ghias, R., Mittal, R., Dong, H., 2007. A Sharp Interface Immersed Boundary Method for Compressible Viscous Flows. Journal of Computational Physics, Volume 225(1), pp. 528553

Grove, A.S., Shair, F.H., Petersen, E.E., 2006. An Experimental Investigation of the Steady Separated Flow past a Circular Cylinder. Journal of Fluid Mechanics, Volume 19(1), pp. 60-80

Henderson, R.D., 1995. Details of the Drag Curve near the Onset of Vortex Shedding. Physics of Fluids, Volume 7(9), pp. 2102-2104

Kays, W.M., Crawford, M.E., 1993. Convective Heat and Mass Transfer. New York: McGrawHill

Lachouette, D., S. Bonelli, F., Golay, P., Seppecher, 2009. Numerical Modelling of Interfacial Soil Erosion. In: 19ème Congrès Francais de Mécanique

Lastiwka, M., Basa, M., Quinlan, N.J., 2009. Permeable and Non-reflecting Boundary Conditions in SPH. International Journal for Numerical Methods in Fluids, Volume 61(7), pp. 709-724

Leduc J., 2010. Etude Physique et Numérique de L'écoulement Dans un Système D’injection de Turbine Pelton (Physical and Numerical Study of Flow in a Pelton Turbine Injection System). Ph.D. Thesis, École Centrale de Lyon, Ecully, France

Marongiu, J.C., 2007. Méthode Numérique Lagrangienne Pour la Simulation D'écoulements à Surface Libre - Application Aux Turbines Pelton (Lagrangian Numerical Method for Simulation of Free Surface Flow - Application to Pelton Turbines). Ph.D. Thesis, École Centrale de Lyon, Ecully, France

Mercier, F., 2013. Modélisation Numérique de L'érosion d'un sol Cohésif par un écoulement Turbulent (Numerical Modeling of Erosion of a Cohesive Soil by a Turbulent Flow). Ph.D. Thesis, Université d'Aix-Marseille, Provence, France

Mittal, S., Kumar, V., Raghuvanshi, A., 1997. Unsteady Incompressible Flows Past Two Cylinders in Tandem and Staggered Arrangements. International Journal for Numerical Methods in Fluids, Volume 25(11), pp. 1315-1344

Monaghan, J.J., 1992. Smoothed Particle Hydrodynamics. Annual Review of Astronomy and Astrophysics, Volume 30(1), pp. 543-574

Morris, J.P., Fox, P.J., Zhu, Y., 1997. Modeling Low Reynolds Number Incompressible Flows using SPH. Journal of Computational Physics, Volume 136(1), pp. 214-226

Norberg, C., 1993. Flow around Rectangular Cylinders: Pressure Forces and Wake Frequencies. Journal of Wind Engineering and Industrial Aerodynamics, Volume 49(1-3), pp. 187-196

Posdziech, O., Grundmann, R., 2007. A Systematic Approach to the Numerical Calculation of Fundamental Quantities of the Two-dimensional Flow over a Circular Cylinder. Journal of Fluids and Structures, Volume 23(3), pp. 479-499

Rajani, B.N., Kandasamy, A., Majumdar, S., 2009. Numerical Simulation of Laminar Flow past a Circular Cylinder. Applied Mathematical Modelling, Volume 33(3), pp. 1228-1247 
Sahu, A.K., Chhabra, R.P., Eswaran, V., 2009. Effects of Reynolds and Prandtl Numbers on Heat Transfer from a Square Cylinder in the Unsteady Flow Regime. International Journal of Heat and Mass Transfer, Volume 52(3-4), pp. 839-850

Sibille, L., Lomin, F., Marot, D., 2012. Investigation in Modelling Piping Erosion with a Coupled "Lattice Boltzmann - Discrete Element" Numerical Method. In: International Conference on Scour Erosion (ISCE6), Paris, France, pp. 551-558

Sjah, J., Vincens, E., Leboeuf, F., Chaze, M., 2013. Modélisation de L'écoulement Visqueux Autour d'un Cylindre Fixe Par la Method SPH-ALE (Modelling Viscous Flow around a Fixed Cylinder using the SPH-ALE Method). $31^{\text {èmes }}$ Recontres de l'AUGC (Association Universitaire de Génie Civil), ENS (Ecole Normale Supérieure), Cachan, France

Tait, P., 1888. Report on Some of the Physical Properties of Fresh Water and Sea Water. Technical Report 2, Physical Chemistry

Vila, J.P., 1999. On Particle Weighted Methods and Smoothed Particle Hydrodynamics. Mathematical Models and Methods in Applied Sciences, Volume 9(2), pp. 161-209

Wan, C.F., Fell, R., 2002. Investigation of Internal Erosion and Piping of Soils in Embankment Dams by the Slot Erosion Test and the Hole Erosion Test. Technical Report, UNICIV Report no. R-412, University of New South Wales, Sydney, Australia

Wan, C.F., Fell, R., 2004. Investigation of Rate of Erosion of Soils in Embankment Dams. Journal of Geotechnical and Geoenvironmental Engineering, Volume 130(4), pp. 373-380

Xu, Y., Zhang, L.M., 2009. Breaching Parameters for Earth and Rockfill Dams. Journal of Geotechnical and Geoenvironmental Engineering, Volume 135(12), pp. 1957-1970

Zdravkovich, M.M., 1997. Flow around circular cylinders. Oxford, UK: Oxford University Press 